\title{
Autoria única nas áreas de informação no Brasil: características da produção de artigos científicos (2011-2016)
}

\author{
Daniela Gralha de Caneda Queiroz \\ Doutoranda; Universidade de Brasília, Brasília, DF, Brasíl; \\ daniela.caneda@ufrgs.br \\ Jayme Leiro Vilan Filho \\ Doutor; Universidade de Brasília, Brasília, DF, Brasíl; \\ jleiro@unb.br
}

Resumo: Objetiva investigar a publicação de artigos em autoria única nas áreas de Arquivologia, Biblioteconomia, Ciência da Informação e Museologia no Brasil. Faz uma análise bibliométrica de 1036 artigos, publicados entre os anos de 2011 e 2016, indexados na base de dados ABCDM. Apresenta tabelas, gráficos e figuras que apontam: taxa média negativa de produção de $12,67 \%$; $80,66 \%$ de autores transientes; Espanha e Portugal como países cujos autores mais publicaram nos periódicos brasileiros; a região sudeste e a Universidade de São Paulo como as que mais tiveram publicações; o periódico Acervo foi o que mais publicou artigos desse tipo; Ciência da Informação como a área e tema de pesquisa mais frequente. Conclui que as características da produção científica em autoria única apresentam diferenças em relação às características da produção científica em autoria múltipla, com sugestão de estudo qualitativo futuro.

Palavras-chave: Comunicação científica. Produção científica. Autoria única. Áreas de informação. Brasil.

\section{Introdução}

O progresso econômico e social de um país está ligado ao seu nível de desenvolvimento em ciência, tecnologia e inovação (CTI), alcançado através da pesquisa. Ziman (1988) compreende que ciência e tecnologia juntas formam uma instituição social maior, calcada na geração, acumulação e utilização de conhecimento. Tal conhecimento é essencial para a evolução de uma nação. Desse modo, o autor evidencia a dificuldade em distinguir pesquisa e desenvolvimento.

Assim, é evidente a relevância da valorização e do investimento científico, atingindo a excelência e a qualidade, objetivando o progresso. Em 
vista disso, esse investimento precisa ser administrado e gerido. E, para isso, é necessário um mapeamento da ciência que possibilite tomadas de decisão em investimentos específicos. Assim, mapear uma área permite modernizar instituições, reduzir gastos e pesquisar áreas mais interessantes (informação verbal $^{1}$ ). Para a Organização das Nações Unidas para a Educação, a Ciência e a Cultura - UNESCO (2015, p. 34), monitorar os sistemas de ciência e inovação permite "[...] direcionar investimentos em P\&D e auxiliar na tomada de decisões políticas, fomentando a competitividade." Motoyama (2004) também coloca que é necessário que se conheça os fatos e os dados a respeito da ciência para se aprender e para ganhar capacidade de previsão. Logo, é evidente a importância de investigar a ciência.

Em virtude disso, essa pesquisa investigará a produção científica da autoria única nas áreas de informação no Brasil, aqui subentendidas como Arquivologia, Biblioteconomia, Ciência da Informação e Museologia, compreendidas neste estudo como áreas distintas entre si. A definição de pesquisar a autoria única surgiu da percepção de que, embora represente cerca de um terço da produção de artigos de periódicos no Brasil, o que é apontado por Vilan Filho (2016) e Gabriel Junior (2017), ela não é investigada; justificando, desse modo, essa pesquisa. Além disso, as poucas pesquisas existentes a respeito da autoria única não focam as áreas de informação do Brasil.

Em vista disso, como objetivo geral desta pesquisa, procura-se aqui descrever as características da produção científica da autoria única das áreas de informação brasileiras, através dos artigos de periódicos indexados na base de dados ABCDM, no período de 2011 a 2016. Para tanto, na qualidade de objetivos específicos, serão estabelecidos: a evolução da produção dos artigos ao longo dos anos; os autores com maior produção científica; o perfil dos autores (quanto ao gênero e vínculo institucional atrelado às regiões brasileiras); e os periódicos de publicação, áreas e temas de pesquisa. 


\section{Metodologia}

Essa pesquisa é do tipo bibliométrica, descritiva, com abordagem quantitativa do problema, de natureza aplicada e em nível macro. Foi escolhida a base de dados ABCDM, da Universidade de Brasília (UnB), em função da sua cobertura, credibilidade e usabilidade. Ela possui mais de doze mil referências de artigos de periódicos brasileiros e portugueses das áreas de informação (Arquivologia, Biblioteconomia, Ciência da Informação, Documentação e Museologia), as quais cobrem artigos, artigos de revisão e relatos de pesquisa de mais de trinta periódicos do Brasil e de Portugal, do período entre os anos de 1963 a 2016 no momento da presente pesquisa. A ABCDM não está disponível on-line; a coleta de dados foi realizada em cópia da base fornecida por seu editor ${ }^{2}$. Para informações complementares, também foi consultada a Plataforma Lattes, do Conselho Nacional de Desenvolvimento Científico e Tecnológico CNPq.

Foram coletados os dados referentes ao: (1) ano de publicação e nome do periódico; (2) título, palavras-chave e área do artigo; (3) nome, vínculo institucional e gênero do autor de 1036 artigos de periódicos brasileiros das áreas de informação de autoria única ${ }^{3}$ indexadas na ABCDM, entre os anos de 2011 e 2016 (último ano de cobertura completa), em maio de 2018. Os resultados dessa coleta foram inseridos no Excel para análise estatística e elaboração de gráficos e tabelas. Também foram utilizados o OpenRefine, para limpeza das palavras-chave; o WordClouds, para construção da nuvem das palavras-chave; e o Philcarto, para construção do mapa de distribuição dos artigos pelo Brasil.

\section{Apresentação e análise dos resultados}

Como já descrito, foram recuperadas 1036 referências de artigos de periódicos brasileiros de autoria única das áreas de informação, publicados entre os anos de 2011 e 2016. A Tabela 1 apresenta a distribuição desses artigos, ao longo dos anos analisados, comparada à autoria múltipla. 
Daniela Gralha de Caneda Queiroz e Jayme Leiro Vilan Filho

Tabela 1 - Número de artigos de autoria única (AU) e de autoria múltipla (AM) das áreas de informação indexados na ABCDM entre 2011 e 2016 (n=3105)

\begin{tabular}{cccccc}
\hline Ano & F(AU) & \%(AU) & F(AM) & \%(AM) & Total anual \\
\hline 2011 & 219 & 42,28 & 299 & 57,72 & 518 \\
2012 & 217 & 37,87 & 356 & 62,13 & 573 \\
2013 & 183 & 34,92 & 341 & 65,08 & 524 \\
2014 & 152 & 30,71 & 343 & 69,29 & 495 \\
2015 & 162 & 29,67 & 384 & 70,33 & 546 \\
2016 & 103 & 22,94 & 346 & 77,06 & 449 \\
Total geral & $\mathbf{1 0 3 6}$ & $\mathbf{3 3 , 3 7}$ & $\mathbf{2 0 6 9}$ & $\mathbf{6 6 , 6 3}$ & $\mathbf{3 1 0 5}$ \\
\hline
\end{tabular}

Legenda: F = frequência; AU - autoria única; AM - autoria múltipla. Fonte: Dados da pesquisa.

Em relação ao total de artigos (autoria única e autoria múltipla), à autoria única correspondeu a 33,37\% (cerca de 1/3) no período em questão. Observa-se na Tabela 1 que, entre o primeiro e o último ano analisados, a produção de artigos de autoria única diminuiu, com uma taxa média negativa de produção de $12,67 \%$, enquanto que a produção de artigos de autoria múltipla obteve uma taxa média de produção de 3,50\%. No entanto, ao analisar-se o Gráfico 1, percebe-se que o comportamento de oscilação das taxas anuais de crescimento da autoria única e múltipla é parecido, ou seja, quando AM desce, AU também desce, quando $\mathrm{AM}$ sobe, $\mathrm{AU}$ também sobe, mesmo que em proporções diferentes (com exceção do ano de 2014), sendo dependentes da evolução da produção total.

Gráfico 1 - Taxas anuais de crescimento da produção de artigos de autoria única (AU) e de autoria múltipla (AM) das áreas de informação indexados na ABCDM entre 2011 e 2016 $(\mathrm{n}=3105)$

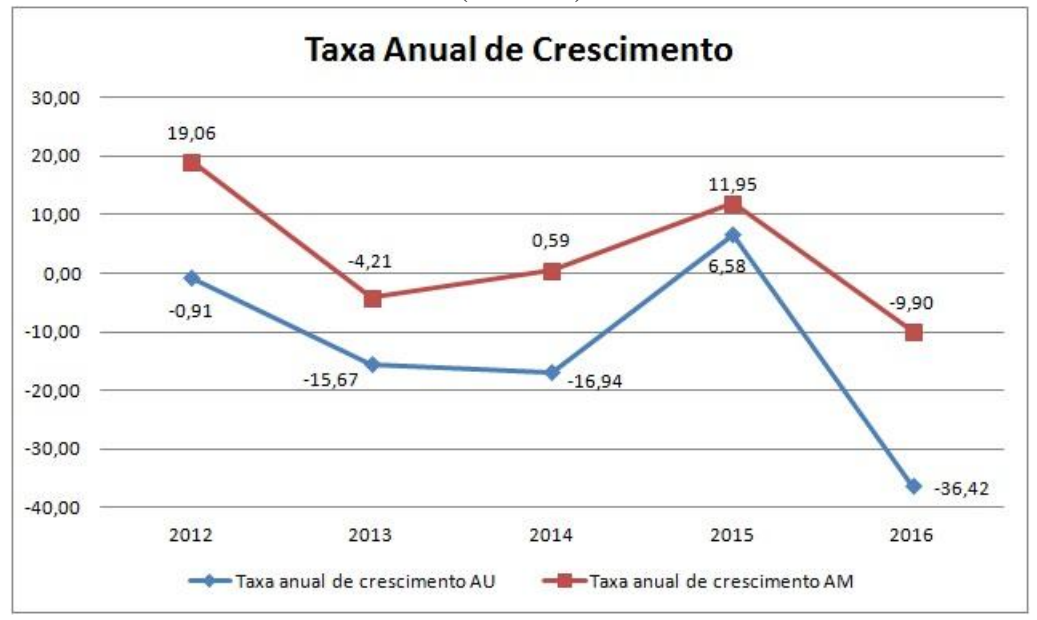

Legenda: AU - autoria única; AM - autoria múltipla.

Fonte: Dados da pesquisa. 
A despeito da taxa média negativa de produção, a área de ciências sociais, da qual fazem parte as áreas de informação, possui índices elevados de autoria única. King (2013), em estudo a respeito da presença da autoria única em 21 áreas de pesquisa na base de dados Web of Science, entre 1981 e 2012, constatou que o percentual de autoria única nas ciências sociais é o mais elevado, correspondendo a 40\% dos artigos. Carvalho e Caregnato (2016), em estudo na BRAPCI ${ }^{4}$, entre 2005 e 2014, encontraram índices de autoria única de 42,65\% nos artigos de periódicos, resultado parecido com o de King (2013).

O comportamento observado na Tabela 1 (de diminuição na produção de artigos de autoria única) pode ser um indicativo de desenvolvimento das áreas de informação. O que é corroborado pela pesquisa de Almeida e Vilan Filho (2017) sobre a evolução da autoria múltipla nos artigos das áreas de informação no Brasil de 2010 a 2015. Os autores encontraram crescimento de coautoria em torno de $77 \%$ para a Biblioteconomia e para a Ciência da Informação; 50\% para a Arquivologia; e 30\% para a Museologia.

Pesquisas sobre as áreas de informação no Brasil (VILAN FILHO; SOUZA; MUELLER, 2008; NASCIMENTO, 2011; VILAN FILHO, 2016) indicam que a autoria única prevalecia até idos do ano 2006, sendo ultrapassada pelos trabalhos de autoria múltipla. Nascimento (2011) credita o aumento da coautoria ao resultado de políticas indiretas de incentivo à produção colaborativa, tais como a distribuição de bolsas-sanduíche e os estágios pósdoutorais.

Entretanto, ao analisar-se o número de elementos de autoria, a proporção entre autoria única e múltipla muda bastante, de acordo com a Tabela 2.

Tabela 2 - Número de elementos de autoria única (AU) e de autoria múltipla (AM) das áreas de informação indexados na ABCDM entre 2011 e 2016 ( $n=6480)$

\begin{tabular}{cccccccc}
\hline Ano & $\mathbf{F}(\mathbf{A U})$ & $\boldsymbol{\%}(\mathbf{A U})$ & $\mathbf{F}(\mathbf{A M})$ & $\mathbf{\%}(\mathbf{A M})$ & $\mathbf{F A}(\mathbf{A M})$ & $\overline{\mathbf{X}}$ & Total anual \\
\hline 2011 & 219 & 22,51 & 754 & 77,49 & 299 & 2,52 & 973 \\
2012 & 217 & 19,51 & 895 & 80,49 & 356 & 2,51 & 1112 \\
2013 & 183 & 17,01 & 893 & 82,99 & 341 & 2,62 & 1076 \\
2014 & 152 & 14,18 & 920 & 85,82 & 343 & 2,68 & 1072 \\
2015 & 162 & 13,42 & 1045 & 86,58 & 384 & 2,72 & 1207 \\
2016 & 103 & 9,90 & 937 & 90,10 & 346 & 2,71 & 1040 \\
Total geral & $\mathbf{1 0 3 6}$ & $\mathbf{1 5 , 9 9}$ & $\mathbf{5 4 4 4}$ & $\mathbf{8 4 , 0 1}$ & $\mathbf{2 0 6 9}$ & $\mathbf{2 , 6 3}$ & $\mathbf{6 4 8 0}$ \\
\hline
\end{tabular}

Legenda: F = frequência; AU - autoria única; AM - autoria múltipla; FA (AM) - frequência dos artigos de autoria múltipla; $\overline{\mathrm{X}}$ - média de autores (AM) por artigos (AM). Fonte: Dados da pesquisa. 
A análise da Tabela 2 permite averiguar que, fato conteste, o número de elementos de autoria múltipla é maior que o de autoria única, esta correspondendo a aproximadamente $1 / 6$ do total geral. No entanto, percebe-se que, na autoria múltipla, a média de número de autores por artigo tem crescido ao longo dos anos.

Os 1036 artigos de autoria única foram escritos por 812 autores diferentes. Entre esses, 695 autores (85,59\%) escreveram um único artigo em autoria única, ou seja, escreveram 695 artigos (67,08\%); os demais 117 autores $(14,40 \%)$ foram responsáveis, então, por escrever 341 artigos $(32,91 \%)$, dando uma média de 2,91 artigos por autor.

Ainda dentre estes 812 autores, 655 (80,66\%) escreveram, no período analisado, somente um artigo que tenha sido publicado em periódicos brasileiros das áreas de informação. Os demais 157 autores (19,33\%) escreveram artigos em coautoria. Parreiras et al. (2006), em pesquisa sobre colaboração e produção científica em Ciência da Informação no Brasil, já haviam destacado a concentração de artigos de autoria única de autores denominados por eles como transientes, ou seja, com um único artigo publicado na área. Da mesma forma, Meza, Sabaj e Matsuda (2017), em artigo cujo objetivo era o de analisar a autoria única na base de dados SciELO Chile, entre os anos de 2010 e 2014, encontraram que, nas ciências sociais, 665 (76,44\%) autores contribuíram com apenas um artigo, ou seja, os autores únicos tendiam a ser ocasionais (escreviam sozinhos e apenas uma vez).

Os autores que tiveram maior produção científica de artigos de autoria única estão representados na Tabela 3. Correspondem ao primeiro quartil com maior produção 88 autores (10,83\%); no entanto, na Tabela 3 somente estão representados os 15 autores com maior produção. O fato de cerca de $10 \%$ dos autores serem responsáveis por $1 / 4$ da produção total de artigos não gerou estranheza, pois, como bem colocam Callon, Courtial e Penan (1995, p. 10) “[...] a comunidade científica se divide em uma elite que publica a maior parte dos artigos e em uma massa de investigadores pouco produtivos [...]”. 
Daniela Gralha de Caneda Queiroz e Jayme Leiro Vilan Filho

Tabela 3 - Autores com maior produção de artigos de autoria única das áreas de informação indexados na ABCDM entre 2011 e 2016 ( $\mathrm{n}=1036)$.

\begin{tabular}{|c|c|c|c|c|c|c|c|c|c|}
\hline $\mathbf{N}$ & Autor & ${\text { Instituiçãa } 0^{5}}$ & UF/País & $\mathbf{F ( A U )}$ & $\%$ & $\% \mathrm{Ac}$ & $\mathbf{F}(\mathrm{AM})$ & FT & $\%$ AU/FT \\
\hline 1 & $\begin{array}{l}\text { Carlos A. A. } \\
\text { Araujo }\end{array}$ & UFMG & $\mathrm{MG}$ & 13 & 1,25 & 1,25 & 22 & 35 & 37,14 \\
\hline 2 & $\begin{array}{l}\text { Jorge Santa } \\
\text { Anna }\end{array}$ & UFES & ES & 12 & 1,16 & 2,41 & 13 & 25 & 48,00 \\
\hline 3 & $\begin{array}{l}\text { Jessica C. } \\
\text { Siqueira }\end{array}$ & USP & SP & 9 & 0,87 & 3,28 & 1 & 10 & 90,00 \\
\hline 4 & $\begin{array}{l}\text { Gustavo S. } \\
\text { Saldanha }\end{array}$ & $\begin{array}{l}\text { IBICT, } \\
\text { UNIRIO, } \\
\text { UFRJ }\end{array}$ & RJ & 7 & 0,68 & 3,96 & 4 & 11 & 63,64 \\
\hline 5 & $\begin{array}{l}\text { Jorge Caldera- } \\
\text { Serrano }\end{array}$ & UEX & Espanha & 7 & 0,68 & 4,63 & 3 & 10 & 70,00 \\
\hline 6 & $\begin{array}{l}\text { Roberto } \\
\text { L.Santos Junior }\end{array}$ & $\begin{array}{l}\text { IBICT, } \\
\text { UNIRIO, } \\
\text { UFPA, } \\
\text { UFRJ }\end{array}$ & RJ, PA & 7 & 0,68 & 5,31 & 1 & 8 & 87,50 \\
\hline 7 & $\begin{array}{l}\text { Ronaldo F. } \\
\text { Araujo }\end{array}$ & UFAL & $\mathrm{AL}$ & 6 & 0,58 & 5,89 & 6 & 12 & 50,00 \\
\hline 8 & Aldo A. Barreto & $\begin{array}{l}\text { CNPq, } \\
\text { IBICT }\end{array}$ & $\mathrm{DF}, \mathrm{RJ}$ & 5 & 0,48 & 6,37 & 1 & 6 & 83,33 \\
\hline 9 & $\begin{array}{l}\text { Bruno C. B. } \\
\text { Soares }\end{array}$ & $\begin{array}{l}\text { UNIRIO, } \\
\text { UFF }\end{array}$ & RJ & 5 & 0,48 & 6,85 & 1 & 6 & 83,33 \\
\hline 10 & $\begin{array}{l}\text { Dalton L. } \\
\text { Martins }\end{array}$ & $\begin{array}{l}\text { SENAC, } \\
\text { USP, UFG }\end{array}$ & $\begin{array}{l}\text { Brasil, SP, } \\
\text { GO }\end{array}$ & 5 & 0,48 & 7,34 & 9 & 14 & 35,71 \\
\hline 11 & $\begin{array}{l}\text { Francisco } \\
\text { C.Souza }\end{array}$ & UFSC & $\mathrm{SC}$ & 5 & 0,48 & 7,82 & 1 & 6 & 83,33 \\
\hline 12 & $\begin{array}{l}\text { Gabrielle F. S. } \\
\text { C. Tanus }\end{array}$ & UFMG & MG & 5 & 0,48 & 8,30 & 3 & 8 & 62,50 \\
\hline 13 & $\begin{array}{l}\text { Jonathas L. C. } \\
\text { S. }\end{array}$ & $\begin{array}{l}\text { UFBA, } \\
\text { UFC }\end{array}$ & $\mathrm{BA}, \mathrm{CE}$ & 5 & 0,48 & 8,78 & 12 & 17 & 29,41 \\
\hline 14 & $\begin{array}{l}\text { Kelley C. G. D. } \\
\text { Gasque }\end{array}$ & UNB & DF & 5 & 0,48 & 9,27 & 5 & 10 & 50,00 \\
\hline 15 & $\begin{array}{l}\text { Rodrigo } \\
\text { Rabello }\end{array}$ & $\begin{array}{l}\text { IBICT, } \\
\text { USP }\end{array}$ & Brasil, SP & 5 & 0,48 & 9,75 & 1 & 6 & 83,33 \\
\hline
\end{tabular}

Entre esses 15 autores com maior produção, é interessante observar que 7 deles apresentaram vínculos institucionais diferentes ao longo do período analisado. Isso pode significar que o pesquisador estava ainda em formação acadêmica, realizando seus estudos em instituição diferente da sua instituição de trabalho, justificando, assim, mais de um vínculo durante o período analisado.

Além disso, apenas um dos autores com maior produção, Jorge CalderaSerrano, está vinculado à instituição estrangeira (Espanha). Ademais, 9 desses autores escreveram mais artigos em autoria única do que em autoria múltipla, conforme coluna "\% AU/FT" da Tabela 3 (aliás, 6 desses autores escreveram 
somente 1 artigo em autoria múltipla durante o período), podendo ser um indicativo de que há uma preferência desses autores por escrever em autoria única.

Em relação ao gênero, os autores dos 1036 artigos encontram-se distribuídos conforme a Tabela 4. Percebe-se que não há diferença significativa entre as quantidades de autores femininos e masculinos. Até o ano de 2012, a autoria única feminina é maior, depois passa a ser menor que a masculina, voltando a ser maior em 2016. O ano de 2012 é o que há maior diferença entre homens e mulheres, sendo o feminino 11,52 pontos percentuais maior.

Tabela 4 - Gênero dos autores dos artigos de autoria única das áreas de informação indexados na ABCDM entre 2011 e $2016(n=1036)$.

\begin{tabular}{cccccc}
\hline Gênero & \multicolumn{2}{c}{ Feminino } & \multicolumn{2}{c}{ Masculino } & \multirow{2}{*}{ Total anual } \\
\cline { 1 - 5 } Ano & F & \% & F & \% & \\
\hline 2011 & 113 & 51,60 & 106 & 48,40 & 219 \\
2012 & 121 & 55,76 & 96 & 44,24 & 217 \\
2013 & 89 & 48,63 & 94 & 51,37 & 183 \\
2014 & 74 & 48,68 & 78 & 51,32 & 152 \\
2015 & 78 & 48,15 & 84 & 51,85 & 162 \\
2016 & 53 & 51,46 & 50 & 48,54 & 103 \\
Total geral & $\mathbf{5 2 8}$ & $\mathbf{5 0 , 9 7}$ & $\mathbf{5 0 8}$ & $\mathbf{4 9 , 0 3}$ & $\mathbf{1 0 3 6}$ \\
\hline \multicolumn{5}{c}{ Legenda: F= frequência. } \\
& Fonte: Dados da pesquisa. \\
\end{tabular}

Apesar de neste estudo não ter sido encontrada diferença quantitativa significativa em relação ao gênero dos autores, outras pesquisas indicam o contrário. Por exemplo, Vilan Filho (2009), em estudo a respeito da produção de artigos em coautoria e gênero dos autores nos periódicos científicos nas áreas de informação no Brasil, de 1972 a 2007, demonstrou que esses percentuais foram de $61,55 \%$ para o gênero feminino e de $38,44 \%$ para o gênero masculino (levando em consideração só os resultados de autoria única). Soma-se a esse estudo a pesquisa de Nascimento e Gomes (2012), em que verificaram as características e tendências da autoria e da coautoria, entre os anos de 2000 e 2010, em seis revistas da área de Ciência da Informação no Brasil, resultando em 1439 autores, com 849 (59,00\%) mulheres e 589 (40,93\%) homens.

Além disso, Hayashi et al. (2018), em pesquisa sobre a relação entre gênero e autoria nos estudos bibliométricos apresentados entre 1994 e 2016, no 
Encontro Nacional de Pesquisa em Ciência da Informação - ENANCIB, observaram que, na autoria única, a participação feminina (48) predominava sobre a masculina (12); e, na coautoria, a superioridade feminina (297) mantinha-se diante da masculina (55), acontecendo o mesmo em relação à coautoria mista nos 123 trabalhos analisados, em que participavam homens (163) e mulheres (175). Da mesma forma, em estudo de Sousa e Perucchi (2013) sobre a frequência da produção científica de mulheres e homens nos artigos publicados também nos anais do XIII ENANCIB, foram encontrados, em 248 trabalhos analisados, 46 trabalhos femininos e 20 masculinos de autoria única; na autoria múltipla, encontraram-se 73 trabalhos nos grupos formados somente por mulheres e 18 trabalhos nos grupos formados só por homens; e, nos grupos mistos, encontraram como primeiro autor 56 mulheres e 35 homens.

Isto posto, neste estudo esperava-se obter percentuais semelhantes aos apresentados acima (mais mulheres do que homens), mas não foi o encontrado. Dessa forma, pode-se inferir que períodos mais recentes parecem ter evoluído para uma maior paridade entre homens e mulheres na produção de autoria única (ainda na pesquisa de Vilan Filho (2009), nos últimos anos analisados (2000 a 2007), já se percebia uma leve tendência de decréscimo na quantidade de mulheres). Assim, o percentual de autoria única feminino vem caindo paulatinamente ao longo dos anos, tendo atingido o equilíbrio nos anos analisados nesta pesquisa, em que apresenta mediana de 50,07\%.

Os artigos dessa pesquisa provieram de autores de 28 países e de 285 instituições diferentes, sendo que 3 artigos não tinham a informação de vínculo institucional e 2 deles não tinham a informação de país do autor. Assim, entre os 1036 artigos, 81,27\% eram de autores vinculados ao Brasil, como já era esperado. Além disso, 57,64\% das instituições eram brasileiras, conforme podese observar na Tabela 5. 
Daniela Gralha de Caneda Queiroz e Jayme Leiro Vilan Filho

Tabela 5 - Países com maior número de artigos de autoria única das áreas de informação por número de instituições, indexados na ABCDM entre 2011 e 2016

\begin{tabular}{llccccc}
\hline $\mathbf{N}$ & \multicolumn{1}{c}{ Países } & F art. (1036) & \% & F inst. (288) & \% & Média art./inst. \\
\hline 1 & Brasil & 842 & 81,27 & 166 & 57,64 & 5,07 \\
2 & Espanha & 42 & 4,05 & 21 & 7,29 & 2,00 \\
3 & Portugal & 33 & 3,19 & 17 & 5,90 & 1,94 \\
4 & Estados Unidos & 20 & 1,93 & 17 & 5,90 & 1,18 \\
5 & França & 16 & 1,54 & 9 & 3,13 & 1,78 \\
6 & México & 11 & 1,06 & 5 & 1,74 & 2,20 \\
\hline
\end{tabular}

Legenda: $\mathrm{N}$ = ordem dos países; $\mathrm{F}$ art. - frequência de artigos; $\mathrm{F}$ inst. - frequência de instituições. Fonte: Dados da pesquisa.

Os países que mais publicaram artigos nos periódicos brasileiros foram Espanha e Portugal. Mas, ao analisar-se o número de instituições, Espanha fica a frente de Portugal, que aparece empatada com os Estados Unidos. E, ao examinar-se a média de artigos por instituição, seguido ao Brasil, encontram-se Uruguai (com 3 artigos/instituição, que não aparece na Tabela 5 por estar em $9^{\circ}$ lugar em se tratando de quantidade de artigos; no caso, 6 artigos para 2 instituições) e México com as médias mais altas. Depois da América do Sul, o continente que mais apareceu foi a Europa, seguida da América do Norte, respectivamente com $83,37 \%, 11,22 \%$ e $3,58 \%$ dos artigos publicados.

Tal resultado deu-se, provavelmente, em função da proximidade dos idiomas espanhol e português (são línguas latinas). Além disso, conforme dados da Distribuição de bolsas de graduação e pós-graduação no exterior por país de destino da GeoCapes (2016), nos programas de pós-graduação em Ciência da Informação e Museologia, a região ibérica é relevante na concessão de bolsas: as bolsas de doutorado pleno estão principalmente em Portugal e Espanha, além de Estados Unidos, França e Reino Unido em menor número; já as bolsas de doutorado sanduíche estão nos Estados Unidos, Espanha, Portugal, México e Itália; e as bolsas de estágio sênior estão na Espanha e França. E, ainda que se pudesse ponderar que estudos de pós-graduação implicassem trabalhos em coautoria, pesquisa de Queiroz e Vilan Filho (2018) apresenta que nem sempre colaborações entre orientandos e orientadores resultam em coautoria nas áreas de informação.

A Tabela 6 apresenta a distribuição dos artigos (até o segundo quartil) por unidade federativa (UF) brasileira. 
Tabela 6 - Unidades federativas brasileiras com maior número de artigos de autoria única das áreas de informação por número de instituições, indexados na ABCDM entre 2011 e 2016

\begin{tabular}{cccccccc}
\hline $\mathbf{N}$ & $\mathbf{U F}$ & $\begin{array}{c}\text { F art. } \\
(\mathbf{1 0 3 6})\end{array}$ & $\boldsymbol{\%}$ & $\begin{array}{c}\text { F inst. } \\
(\mathbf{2 8 5})\end{array}$ & $\boldsymbol{\%}$ & $\begin{array}{c}\text { Média } \\
\text { art./inst. }\end{array}$ & $\begin{array}{c}\text { \% F art. } \\
\text { AC. }\end{array}$ \\
\hline 1 & RJ & 179 & 17,28 & 26 & 9,03 & 6,88 & 17,28 \\
2 & SP & 157 & 15,15 & 23 & 7,99 & 6,83 & 32,43 \\
3 & MG & 87 & 8,40 & 18 & 6,25 & 4,83 & 40,83 \\
4 & RS & 71 & 6,85 & 19 & 6,60 & 3,74 & 47,68 \\
\hline
\end{tabular}

Legenda: $\mathrm{N}$ = ordem das unidades federativas; $\mathrm{F}$ art. - frequência de artigos; $\mathrm{F}$ inst. - frequência de instituições; \% F art. AC. = porcentagem acumulada dos artigos. E onde: RJ - Rio de Janeiro; SP - São Paulo; MG - Minas Gerais; RS - Rio Grande do Sul.

Fonte: Dados da pesquisa.

Destaque para os estados do Rio de Janeiro e São Paulo, pois foram os que apresentaram maior quantidade de artigos publicados, assim como maior quantidade de instituições. Entretanto, as maiores médias de artigo/instituição são dos estados do Espírito Santo, Ceará e Alagoas, com 16, 9,5 e 8 artigos/instituição, respectivamente. Os estados do Acre, Amapá, Rondônia, Roraima e Tocantins não apareceram nessa pesquisa.

A Figura 1 permite que se visualize melhor a produção de artigos por unidade federativa.

Figura 1 - Distribuição dos artigos de autoria única das áreas de informação pelas unidades federativas brasileiras, indexados na ABCDM entre 2011 e 2016 ( $\mathrm{n}=1036)$.

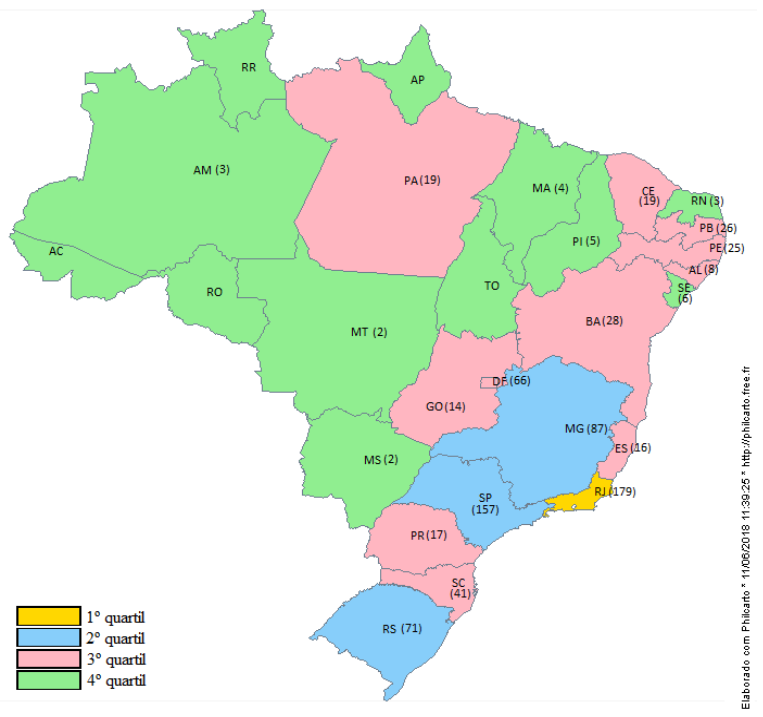

Legenda: o número entre parênteses indica a quantidade de artigos.

$1^{\circ}$ quartil - Rio de Janeiro (RJ); $2^{\circ}$ quartil - Minas Gerais (MG); Rio Grande do Sul (RS) e São Paulo (SP); $3^{\circ}$ quartil - Alagoas (AL), Bahia (BA), Ceará (CE), Distrito Federal (DF), Espírito

Santo (ES), Goiás (GO), Pará (PA), Paraíba (PB), Pernambuco (PE), Paraná (PR) e Santa Catarina (SC); $4^{\circ}$ quartil - Amazonas (AM), Maranhão (MA), Mato Grosso do Sul (MS), Mato Grosso (MT), Piauí (PI), Rio Grande do Norte (RN) e Sergipe (SE) - Acre (AC), Amapá (AP), Rondônia (RO), Roraima (RR) e Tocantins (TO) sem produção.

Fonte: Dados de pesquisa. 
Através da Figura 1 constata-se que a região sudeste foi a que mais produziu artigos, com 42,37\% do total (439). Após, aparecem as regiões sul, nordeste e centro-oeste, com 12,45\% (129), 11,97\% (124) e 8,11\% (84), respectivamente. A região norte foi a que apresentou menor produção: 2,12\% (22).

A Tabela 7 apresenta as instituições (segundo quartil) que tiveram o maior número de artigos publicados. Dentre os artigos brasileiros, 44 (4,25\%) estavam vinculados a $16(5,56 \%)$ instituições de esfera nacional, não sendo identificada a unidade federativa (nestes casos, foi contabilizado como "Brasil'), como, por exemplo, Empresa Brasileira de Pesquisa Agropecuária (EMBRAPA) e Instituto Nacional do Seguro Social (INSS), entre outras.

Tabela 7 - Instituições com maior número de artigos de autoria única nas áreas de informação, indexados na ABCDM entre 2011 e $2016(n=1036)$

\begin{tabular}{llccc}
\hline $\mathbf{N}$ & \multicolumn{1}{c}{ Instituição (n=288) } & F & \% & \% Ac \\
\hline 1 & Universidade de São Paulo (USP) & 66 & 6,37 & 6,37 \\
2 & Universidade Federal de Minas Gerais (UFMG) & 60 & 5,79 & 12,16 \\
3 & Universidade de Brasília (UnB) & 58 & 5,60 & 17,76 \\
4 & Universidade Federal do Estado do Rio de Janeiro (UNIRIO) & 52 & 5,02 & 22,78 \\
5 & Universidade Federal do Rio de Janeiro (UFRJ) & 39 & 3,76 & 26,54 \\
6 & Universidade Estadual Paulista Júlio de Mesquita Filho (UNESP) & 35 & 3,38 & 29,92 \\
7 & Universidade Federal Fluminense (UFF) & 33 & 3,19 & 33,11 \\
\hline 8 & Universidade Federal do Rio Grande do Sul (UFRGS) & 28 & 2,70 & 35,81 \\
9 & Universidade Federal da Bahia (UFBA) & 24 & 2,32 & 38,13 \\
10 & Universidade Federal de Pernambuco (UFPE) & 22 & 2,12 & 40,25 \\
11 & Universidade Federal da Paraíba (UFPB) & 21 & 2,03 & 42,28 \\
12 & Instituto Brasileiro de Informação em Ciência e Tecnologia & 20 & 1,93 & 44,21 \\
& (IBICT) & 18 & 1,74 & 45,95 \\
13 & Universidade Federal de Santa Catarina (UFSC) & 18 & 1,74 & 47,68 \\
14 & Universidade Federal do Ceará (UFC) & 16 & 1,54 & 49,23 \\
15 & Universidade Federal do Espírito Santo (UFES) & 15 & 1,45 & 50,68 \\
\hline 16 & Universidade Estadual de Campinas (UNICAMP) & & \\
\hline
\end{tabular}

Legenda: $\mathrm{N}$ = ordem das instituições; $\mathrm{F}$ = frequência;\% Ac = porcentagem acumulada.

Fonte: Dados da pesquisa.

À exceção da UnB, da região centro-oeste do Brasil, as instituições do primeiro quartil são da região sudeste, a qual apresenta produção científica significativa nas áreas brasileiras de informação, como descrevem Villalobos e Santos (2015), justificando os estados de São Paulo e Rio de Janeiro como os que apresentaram maior quantidade de artigos publicados e, consequentemente, 
a região sudeste, conforme comentado em parágrafos anteriores. Na Tabela 7 pode-se observar que há predominância numérica das instituições localizadas na região sudeste, seguidas da região nordeste.

Já Melo e Vilan Filho (2017), em pesquisa sobre as instituições com maior produção nas áreas de informação, porém em trabalhos do ENANCIB, entre 2010 e 2015, encontraram resultados diferentes dos daqui, evidenciando diferenças de produção institucional entre canais de comunicação. Entretanto, em relação a essas diferenças, deve-se considerar a possibilidade levantada por Vilan Filho (2014), em trabalho que compara os índices de autoria, que sugere a existência de correspondência sincrônica com 5 anos de intervalo entre os periódicos das áreas de informação e o ENANCIB, pelos resultados obtidos os fenômenos aconteceriam primeiramente no evento (ENANCIB) e depois nos periódicos. Os autores obtiveram como instituições com maior produção a UFMG, UFPB (aqui em $11^{\circ}$ lugar) e UNESP (aqui na $6^{a}$ posição).

Em relação às instituições estrangeiras, destaque para Universidad de Extremadura (UEX), Universidade Nacional Autónoma de México (UNAM) e Universidade do Porto (UP), empatadas na $24^{\text {a }}$ colocação, com 7 artigos cada uma $(0,68 \%)$. Toda a produção de artigos de periódicos da UEX veio de um único pesquisador, Jorge Caldera-Serrano (Tabela 3). Na pesquisa de Melo e Vilan Filho (2017), a Universidade Carlos III de Madrid (UC3M) e a UP foram as instituições que mais apareceram; coincidindo o destaque da UP em ambas as pesquisas.

Os 1036 artigos analisados nessa pesquisa foram publicados em 28 diferentes periódicos. O Gráfico 2 mostra a distribuição dos periódicos e de seus artigos publicados por ano. 
Gráfico 2 - Número de artigos e de periódicos por ano referentes aos artigos de autoria única das áreas de informação, indexados na ABCDM entre 2011 e 2016 (n=1036)

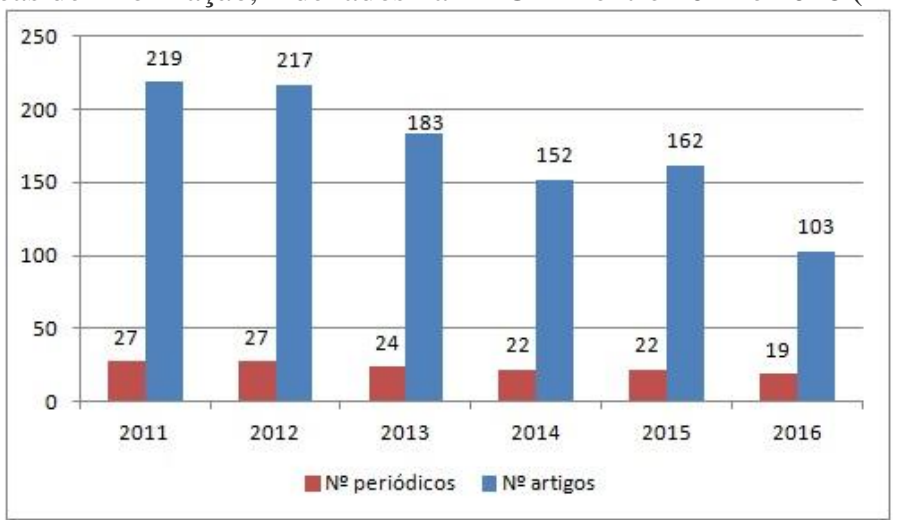

Fonte: Dados da pesquisa.

Ao longo dos anos, a média de artigos em autoria única por publicação ficou em 7,24. A menor média aconteceu no ano de 2016, com 5,42; e a maior média ocorreu no ano de 2011, com média de 8,11. A Tabela 8 apresenta os periódicos que mais tiveram publicações desses artigos de autoria única (segundo quartil).

Tabela 8 - Periódicos brasileiros que mais publicaram artigos de autoria única das áreas de informação, indexados na ABCDM entre 2011 e 2016 ( $n=1036)$

\begin{tabular}{|c|c|c|c|c|c|c|c|}
\hline $\mathbf{N}$ & Periódico & $\mathbf{F}(\mathbf{A U})$ & $\%$ & $\%$ Ac & $\mathbf{F}(\mathbf{A M})$ & FT & $\% \mathrm{AU} / \mathbf{P}$ \\
\hline 1 & Acervo & 125 & 12,07 & 12,07 & 42 & 167 & 74,85 \\
\hline 2 & Em Questão & 64 & 6,18 & 18,24 & 160 & 224 & 28,57 \\
\hline 3 & $\begin{array}{l}\text { Perspectivas em Ciência da } \\
\text { Informação }\end{array}$ & 54 & 5,21 & 23,46 & 258 & 312 & 17,31 \\
\hline 4 & $\begin{array}{l}\text { Revista Digital de Biblioteconomia } \\
\text { e Ciência da Informação }\end{array}$ & 51 & 4,92 & 28,38 & 84 & 135 & 37,78 \\
\hline 5 & Estudos Históricos & 50 & 4,83 & 33,20 & 10 & 60 & 83,33 \\
\hline 6 & Museologia e Interdisciplinaridade & 47 & 4,54 & 37,74 & 16 & 63 & 74,60 \\
\hline 7 & Ponto de Acesso & 47 & 4,54 & 42,28 & 62 & 109 & 43,12 \\
\hline 8 & DataGramaZero & 45 & 4,34 & 46,62 & 112 & 157 & 28,66 \\
\hline 9 & Encontros Bibli & 45 & 4,34 & 50,97 & 135 & 180 & 25,00 \\
\hline
\end{tabular}

Legenda: F = frequência; AU - autoria única; \% Ac = porcentagem acumulada; $\mathrm{AM}$ - autoria múltipla; FT = frequência total; $\mathrm{P}$ - total de artigos no periódico.

Fonte: Dados da pesquisa.

Análise da Tabela 8 permite verificar que há prevalência de três periódicos (primeiro quartil) na publicação de artigos de autoria única, os quais ocupam 23,46\% do total, sendo que o primeiro (Acervo) tem quase o dobro da frequência do segundo colocado (Em Questão). Mas ao observar a última coluna, que relaciona percentuais de autoria única e tamanho da coleção, pode- 
se constatar que os periódicos que possuem maior percentual relativo de autoria única estão ligados às áreas da Museologia, talvez porque a autoria única seja uma característica desta área em específico, como comentado mais adiante. Deve-se considerar nesta análise que o tamanho da coleção dos periódicos varia muito, explicando as diferenças percentuais entre as colunas "\%" e "\% AU/P".

Em relação às áreas de pesquisa, foram identificadas: Arquivologia (A), Biblioteconomia (B), Ciência da Informação (C), Documentação (D) e Museologia (M); além de outros campos de pesquisa $(\mathrm{O})$, tais como História, Comunicação e Administração (Gráfico 3). Foram identificados também artigos pertencentes a mais de uma área de pesquisa, sendo considerados como artigos interdisciplinares (podendo ser, por exemplo, $\mathrm{AB}$, ou $\mathrm{CD}$, ou $\mathrm{BO}$, etc.). A análise dos 1036 artigos implicou, então, 24 tipos diferentes de classificações dessas publicações.

Gráfico 3 - Número de artigos por área de pesquisa dos artigos de autoria única das áreas de informação, indexados na ABCDM entre 2011 e 2016 ( $n=1036)$.

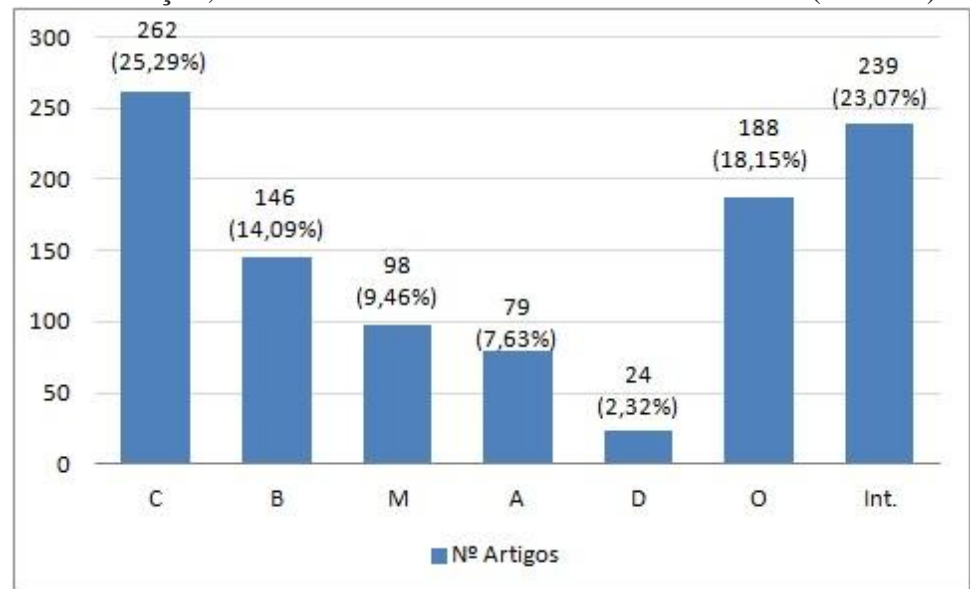

Legenda: C - Ciência da Informação; B - Biblioteconomia; M - Museologia; A - Arquivologia; D - Documentação; O - outras áreas; e Int. - artigos interdisciplinares.

Fonte: Dados da pesquisa.

Almeida e Vilan Filho (2017) encontraram um percentual de 33,57\% de artigos de áreas diferentes que não as áreas de Arquivologia, Biblioteconomia, Ciência da Informação, Documentação e Museologia. Assim, pode-se depreender que os autores que publicam sob forma de autoria única possuem menor tendência em escrever trabalhos interdisciplinares quando comparados àqueles que escrevem em coautoria.

No Gráfico 3, a área de pesquisa que mais aparece é a de Ciência da 
Daniela Gralha de Caneda Queiroz e Jayme Leiro Vilan Filho

Informação, seguida por "Outros", ficando a frente das áreas de Biblioteconomia, Museologia e Arquivologia, e que, somada às consideradas áreas interdisciplinares (Int.), corresponden ao segundo maior percentual de artigos, fortalecendo a característica interdisciplinar dos periódicos brasileiros das áreas de informação. Na pesquisa de Almeida e Vilan Filho (2017), a produção de artigos foi de: Ciência da Informação, 49,68\%; Biblioteconomia, 23,57\%; Arquivologia, 8,70\%; Museologia, 7,99\%; e Documentação, 3,15\%. Comparando-se às pesquisas, verifica-se que houve a continuidade da Ciência da Informação como sendo a área que mais se destaca tanto na autoria única quanto múltipla, mas houve inversão entre Museologia e Arquivologia. De qualquer modo, a Arquivologia e a Museologia possuem menores percentuais porque são áreas de estudo mais recentes quando comparadas à Ciência da Informação e Biblioteconomia.

O número de artigos por área de pesquisa distribuídos ao longo do período analisado está representado no Gráfico 4.

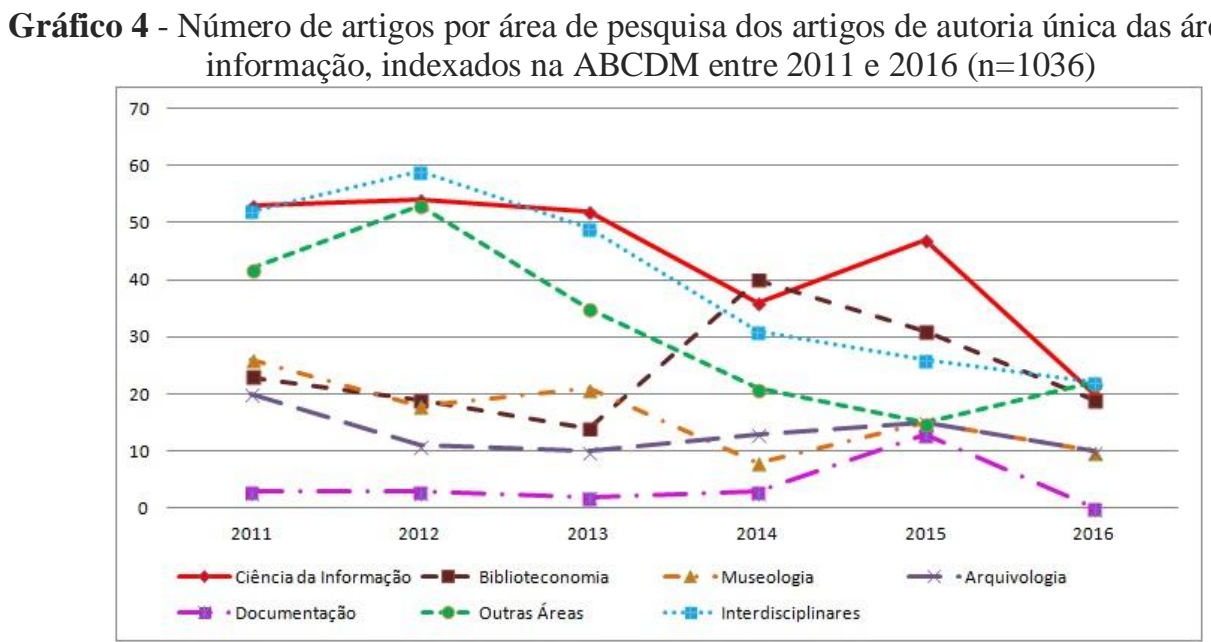

Fonte: Dados da pesquisa.

No Gráfico 4, chama a atenção o comportamento da linha da Ciência da Informação, que se manteve estável entre 2011 e 2013, mas depois sofreu oscilações. A Biblioteconomia, que aparece em declínio nos primeiros anos, dá um salto em 2014, mas volta a cair, embora fique em patamar superior aos anos anteriores. Pode-se dizer que Museologia e Arquivologia apresentam comportamento oscilatório, mas sem grandes variações. A linha 
Interdisciplinares encontra-se em declínio ao longo dos anos e a linha Outros, após período de declínio, parece ter se recuperado no último ano.

Importante destacar que, ainda que estejam sendo investigados artigos publicados em periódicos das áreas de informação, a Arquivologia, Biblioteconomia, Ciência da Informação e Museologia são áreas distintas (TANUS; ARAÚJO, 2012), e, por isso , apresentam comportamentos diferentes de produção científica. Assim, na Biblioteconomia e Ciência da Informação os artigos científicos em autoria única têm decaído nos últimos anos, muito provavelmente em função das políticas indiretas de incentivo à produção colaborativa (distribuição de bolsas-sanduíche e estágios pós-doutorais), como já colocado anteriormente (NASCIMENTO, 2011). Já nas áreas de Arquivologia e Museologia (e também Documentação), o comportamento de produção em autoria única parece manter-se, talvez em vista das características dos próprios pesquisadores dessas áreas, que podem preferir escrever sozinhos; ademais, nestas áreas pode não haver a cultura da escrita colaborativa ou podem prevalecer políticas de editais de fomento à pesquisa em que não existe incentivo à coautoria (QUEIROZ; VILAN FILHO, 2018).

Com o objetivo de identificar os temas de pesquisa mais recorrentes desses artigos, fez-se análise das palavras-chave. Tal análise retornou um total de 3984 palavras-chave, que, após limpeza, resultou 2265 diferentes palavraschave. A Figura 2 apresenta os temas mais frequentes nos artigos (presentes em 4 ou mais artigos).

Figura 2 - Palavras-chave com maior frequência nos artigos de autoria única das áreas de informação indexados na ABCDM entre 2011 e 2016 (n=159)

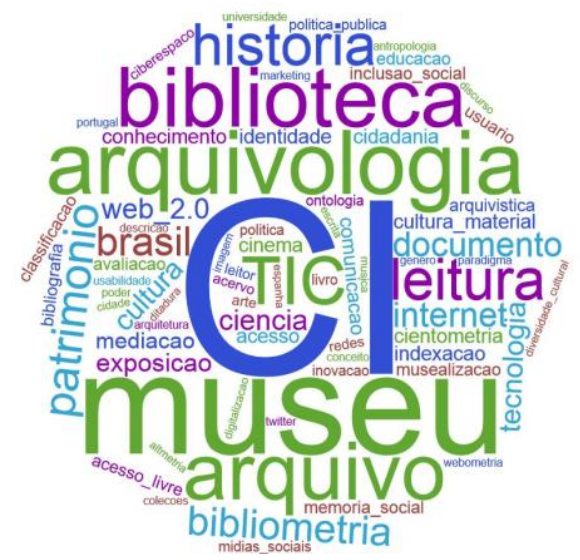

Fonte: Dados da pesquisa. 
Análise das palavras-chave permitiu verificar que não houve supremacia de um tema. Na Figura 2, pode-se observar que a palavra-chave que mais se destacou foi "CI" (Ciência da Informação), que ocupou apenas 2,11\% do total, seguida de "museu", com 1,26\%. As palavras-chave aqui encontradas foram ao encontro dos termos achados na pesquisa de Brito, Vilan Filho e Araújo Júnior (2010) sobre as temáticas da literatura científica das áreas de informação, no período de 1990 a 2007, não demonstrando que os autores que escrevem sozinhos pesquisam temas diferentes.

\section{Considerações finais}

Apesar da taxa média negativa de produção dos artigos de autoria única, considera-se que ainda é significativa a quantidade de trabalhos deste tipo (1/3 da produção total do período de 2011 a 2016). Talvez esse cenário seja reflexo do fato de que esses campos científicos (principalmente a Arquivologia e a Museologia) sejam mais recentes no Brasil, ou talvez seja uma característica das comunidades dessas áreas. Em consideração aos autores, merece atenção o número de pesquisadores (655 ou 80,66\%) que escreveram somente um artigo no período analisado que tenha sido publicado em periódicos brasileiros das áreas de informação indexados na ABCDM. Tal resultado faz jus a um novo estudo, para identificar a formação acadêmica e as informações profissionais desses autores, a fim de tentar entender o resultado aqui encontrado. Além disso, no que se refere ao gênero, encontrou-se um percentual próximo entre os gêneros feminino e masculino, ao contrário do que outros estudos apontam. No que diz respeito às instituições, cogitou-se que a autoria única nas áreas de informação pudesse estar vinculada a instituições com menos tradição em pesquisa, o que foi rejeitado. Da mesma forma, também pensou-se que a autoria única das áreas de informação estivesse presente principalmente em regiões brasileiras em que não existissem programas de pós-graduação vinculados às áreas de informação, o que também foi rechaçado. No que concerne aos periódicos, verificou-se que a publicação de artigos de autoria única não está dispersa, sendo os periódicos da área de Museologia os que proporcionalmente mais publicaram artigos deste tipo, dando indícios de que os pesquisadores 
dessa área tem maior preferência pela autoria única em relação às demais áreas de informação. Já em relação às áreas e temas de pesquisa, o resultado encontrado seguiu tendência das área de informação em geral, ao contrário do que se esperava (de que autores que escrevem sozinhos estudam temas que não são de grande interesse dos pesquisadores). Desse modo, essa pesquisa, que procurou caracterizar a produção científica da autoria única, como parte de tese de doutorado, firma a direção em se estudar qualitativamente as razões desses autores em publicar sozinhos.

\section{Financiamento}

Agradecimento à Coordenação de Aperfeiçoamento de Pessoal de Nível Superior (CAPES).

\section{Referências}

ALMEIDA, L. C.; VILAN FILHO, J. L. Evolução da autoria múltipla nos artigos das áreas de informação no brasil (2010-2015). Brasília: UnB, 2017.

BRITO, M.; VILAN FILHO, J. L.; ARAÚJO JÚNIOR, R. H. Tendências temáticas na comunicação científica em ciências da informação: um estudo bibliométrico/quantitativo através de títulos de artigos de periódicos científicos brasileiros. In: ENCONTRO NACIONAL DE PESQUISA EM CIÊNCIA DA INFORMAÇÃO, 11., 2010, Rio de Janeiro. Anais [...] Rio de Janeiro: ANCIB, 2010. p.1-24.

CALLON, M.; COURTIAL, J.; PENAN, H. Cienciometría: la medición de la actividad científica: de la bibliometría a la vigilancia tecnológica. Gijón: Trea, 1995.

CARVALHO, R. A.; CAREGNATO, S. E. Primeiro vs todos os demais autores citados: estudo empírico em artigos na base bRAPCI. In: ENCONTRO BRASILEIRO DE BIBLIOMETRIA E CIENTOMETRIA, 5., 2016, São Paulo. Anais [...]. São Paulo: USP, 2016. p. 1-8.

GABRIEL JUNIOR, R. F. Panorama dos 45 anos das Revistas de Ciência da Informação no Brasil: um estudo na Brapci. In: ENCONTRO NACIONAL DE PESQUISA EM CIÊNCIA DA INFORMAÇÃO, 18., 2017, Marília. Anais [...]. Marília: UNESP, 2017. p.1-19.

GEOCAPES. Site institucional. Brasília: CAPES, 2016. Disponível em: https://geocapes.capes.gov.br/geocapes. Acesso em: 10 abr. 2018. 
HAYASHI, Maria Cristina Piumbato Innocentini et al. Gênero nos estudos bibliométricos apresentados nos ENANCIBs (1994-2016). Revista ACB: biblioteconomia em santa catarina, Florianópolis, v. 23, n. 1, p. 54-68, dez./mar. 2018.

KING, C. Single-author papers: a waning share of output, but still providing the tools for progress. [S.l.]: Sciencewatch, 2013.

MELO, I.; VILAN FILHO, J. L. Análise da produção de artigos científicos e trabalhos de ENANCIB (2010-2015): instituições mais produtivas. Brasília: $\mathrm{UnB}, 2017$.

MEZA, P.; SABAJ, O.; MATSUDA, K. La Autoría única en SciELO Chile: prácticas autoriales en las áreas de la ciencia. Biblios: journal of librarianship and information science, Pittsburgh, n. 66, p. 11-19, jul. 2017.

MOTOYAMA, S. Ciência e tecnologia no Brasil: para onde? In: MOTOYAMA, S. (org.). Prelúdio para uma história: ciência e tecnologia no Brasil. São Paulo: EDUSP, 2004. p. 14-58.

NASCIMENTO, B. S. A Ciência da Informação no Brasil: um retrato da área através do estudo de autoria e da análise das redes de colaboração científica. 2011. Dissertação (Mestrado em Ciência da Informação) - Universidade Federal da Bahia, Salvador, 2011. $153 \mathrm{f}$.

NASCIMENTO, Bruna Silva do; GOMES, Maria Yêda Falcão Soares de Filgueiras. A Ciência da Informação no Brasil: um retrato da área através do estudo de autoria. In: ENCONTRO NACIONAL DE PESQUISA EM CIÊNCIA DA INFORMAÇÃO, 13., 2012, Rio de Janeiro. Anais [...] Rio de Janeiro: Fiocruz, 2012. p. 1-21.

PARREIRAS, F. S. et al. Rede CI: colaboração e produção científica em ciência da informação no Brasil. Perspectivas em Ciência da Informação, Belo Horizonte, v. 11, n. 3, p. 302-317, set. 2006.

QUEIROZ, Daniela Gralha de Caneda; VILAN FILHO, Jayme Leiro. Autoria Única nos Periódicos Brasileiros das Áreas de Informação: em busca das razões. In: ENCONTRO NACIONAL DE PESQUISA EM CIÊNCIA DA

INFORMAÇÃO, 19., 2018, Londrina. Anais [...] Londrina: UEL, 2018. p. 1-18.

SOUSA, Beatriz Alves; PERUCCHI, Valmira. Gênero na Produção Científica dos Grupos de Trabalho do ENANCIB: análise nos anais do XIII ENANCIB. In: ENCONTRO NACIONAL DE PESQUISA EM CIÊNCIA DA INFORMAÇÃO, 14., 2013, Florianópolis. Anais [...] Florianópolis: UFSC, 2013. p. 1-15.

TANUS, Gabrielle Francinne de Souza Carvalho; ARAÚJO, Carlos Alberto Ávila. Proximidades Conceituais entre Arquivologia, Biblioteconomia, 
Museologia e Ciência da Informação. Biblionline, João Pessoa, v. 8, n. 2, p.2736, 2012.

UNESCO - Organização das Nações Unidas para a Educação, a Ciência e a Cultura (Paris). Relatório de Ciência da UNESCO: rumo a 2030 - visão geral e cenário brasileiro. Paris: UNESCO, 2015. 60 p.

VILAN FILHO, J. L. A Colaboração científica nas áreas de informação no Brasil (1972 - 2013). Revista Ibero-Americana de Ciência da Informação, Brasília, v. 9, n. 1, p. 258-269, jan. 2016.

VILAN FILHO, J. L. Periódicos científicos nas áreas de informação no Brasil: produção de artigos em colaboração e o gênero dos autores. In: ENCONTRO NACIONAL DE PESQUISA EM CIÊNCIA DA INFORMAÇÃO, 10., 2009, João Pessoa. Anais [...] João Pessoa: ANCIB, 2009. p.1-16.

VILAN FILHO, J. L. Produção e colaboração científica nas áreas de informação: comparando artigos de periódicos brasileiros com trabalhos de ENANCIB (1994-2013). In: ENCONTRO NACIONAL DE PESQUISA EM CIÊNCIA DA INFORMAÇÃO, 15., 2014, Belo Horizonte. Anais [...] Belo Horizonte: UFMG, 2014. p. 3395-3408.

VILAN FILHO, J. L.; SOUZA, H. B.; MUELLER, S. Artigos de periódicos científicos das áreas de informação no Brasil: evolução da produção e da autoria múltipla. Perspectivas em Ciência da Informação, Belo Horizonte, v. 13, n. 2, p. 2-17, maio/ago. 2008.

VILLALOBOS, A. P.; SANTOS, L. Análise da produção científica brasileira: uma contribuição da mineração de dados para a Ciência da Informação.

Tendências da Pesquisa Brasileira em Ciência da Informação, Salvador, v. 8, n. 1, p. 34-48, jan./jun. 2015.

ZIMAN, J. An introduction to science studies: the philosophical and social aspects of science and technology. Cambridge: Cambridge University Press, 1988.

\title{
Single authoring in the information areas in Brazil: characteristics of production of scientific articles (2011-2016)
}

\begin{abstract}
This paper intends to study single authorship in Brazilian journal articles in the fields of Archiving, Library Science, Information Science and Museology. It makes a bibliometric analysis of 1036 articles published between 2011 and 2016, indexed at the ABCDM database. It presents tables, graphics and images which shows: a negative average rate production of $12.67 \%$; a transient authorship average of $80.66 \%$; Portugal and Spain as the foreign countries that published the most; Brazilian southeast region and University of
\end{abstract}


São Paulo as the biggest publishers; the Acervo journal as the one who published the most; and Information Science as the most frequent field and theme of research. The conclusion points that single authorship scientific output presents differences in comparison to multiple authorship, and suggests future qualitative studies.

Keywords: Scientific communication. Scientific output. Single authorship. Information areas. Brazil.

Recebido: $14 / 08 / 2018$

Aceito: $14 / 11 / 2018$

${ }^{1}$ Palestra do prof. Elias Sanz-Casado, com título "O papel dos rankings para os novos desafios das universidades", na Faculdade de Biblioteconomia e Comunicação/UFRGS, em 19 nov. 2014.

2 Buscas na ABCDM podem ser feitas pessoalmente na Faculdade de Ciência da Informação da UNB ou pelo endereço jleiro@unb.br; cópias da base podem ser obtidas com autorização do detentor dos direitos patrimoniais: Centro de Apoio ao Desenvolvimento Tecnológico da UNB, pelo endereço act@ @ cdt.unb.br.

3 A base de dados ABCDM está, atualmente, no CDS/ISIS (Computerized Documentation System/Integrated Set of System - sistema de armazenamento e recuperação de informação, desenvolvido pela UNESCO), que oferece diversas facilidades de formatação e exportação de dados com linguagem que possibilita o uso de comandos lógicos. Assim, por conta dessa simplicidade de programação, é possível que se faça o download de dados somente daqueles artigos de autoria única (AU).

${ }^{4}$ Base de dados de periódicos da Ciência da Informação publicados no Brasil.

${ }^{5}$ Onde: $\mathrm{CNPq}$ - Conselho Nacional de Desenvolvimento Científico e Tecnológico; IBICT Instituto Brasileiro de Informação em Ciência e Tecnologia; SENAC - Serviço Nacional de Aprendizagem Comercial; UFAL - Universidade Federal de Alagoas; UFBA - Universidade Federal da Bahia; UFC - Universidade Federal do Ceará; UFES - Universidade Federal do Espírito Santo; UFF - Universidade Federal Fluminense; UFG - Universidade Federal de Goiás; UFMG - Universidade Federal de Minas Gerais; UFPA - Universidade Federal do Pará; UFRJ - Universidade Federal do Rio de Janeiro; UFSC - Universidade Federal de Santa Catarina; UnB - Universidade de Brasília; UNIRIO - Universidade Federal do Estado do Rio de Janeiro; UEX - Universidad de Extremadura; USP - Universidade de São Paulo. E onde também: AL - Alagoas; BA - Bahia; CE - Ceará; DF - Distrito Federal; ES - Espírito Santo; GO - Goiás; MG - Minas Gerais; PA - Pará; RJ - Rio de Janeiro; SC - Santa Catarina; SP - São Paulo. Brasil refere-se às instituições de esfera nacional que não tiveram designadas suas UF. 